ARTICLE

https://doi.org/10.1038/s41467-019-09293-9

\title{
Mechanical behaviour of fluid-lubricated faults
}

\author{
C. Cornelio" ${ }^{1}$ E. Spagnuolo (iD) ${ }^{2}$, G. Di Toro (i) ${ }^{3}$, S. Nielsen (i) ${ }^{4} \&$ M. Violay (i) ${ }^{1}$
}

Fluids are pervasive in fault zones cutting the Earth's crust; however, the effect of fluid viscosity on fault mechanics is mainly conjectured by theoretical models. We present friction experiments performed on both dry and fluid-permeated silicate and carbonate bearingrocks, at normal effective stresses up to $20 \mathrm{MPa}$, with a slip-rate ranging between $10 \mu \mathrm{m} / \mathrm{s}$ and $1 \mathrm{~m} / \mathrm{s}$. Four different fluid viscosities were tested. We show that both static and dynamic friction coefficients decrease with viscosity and that dynamic friction depends on the dimensionless Sommerfeld number $(S)$ as predicted by the elastohydrodynamic-lubrication theory (EHD). Under favourable conditions (depending on the fluid viscosity $(\eta)$, co-seismic slip-rate $(V)$, fault geometry $\left(L / H_{O}^{2}\right)$ and earthquake nucleation depth $\left.\left(\propto \sigma_{\text {eff }}\right)\right)$, EHD might be an effective weakening mechanism during natural and induced earthquakes. However, at seismic slip-rate, the slip weakening distance $\left(D_{c}\right)$ increases markedly for a range of fluid viscosities expected in the Earth, potentially favouring slow-slip rather than rupture propagation for small to moderate earthquakes.

\footnotetext{
${ }^{1}$ Laboratory of Experimental Rock Mechanics (LEMR), École Polytechnique Fédérale de Lausanne (EPFL), Station 18, Lausanne CH-1015, Switzerland.

${ }^{2}$ Istituto Nazionale di Geofisica e Vuolcanologia (INGV), Via di Vigna Murata, 605, Rome 00143, Italy. ${ }^{3}$ Dipartimento di Geoscienze, Università degli Studi di Padova, via G. Gradenigo, 6, Padova 35131, Italy. ${ }^{4}$ Department of Earth Sciences, University of Durham, Stockton Road, Durham DH1 3LE, UK.

Correspondence and requests for materials should be addressed to C.C. (email: chiara.cornelio@epfl.ch)
} 
F luids with variable composition (gas, water, brine, hydrocarbon seepage, wet gouge and frictional melt), rheology and physical state are pervasive within active tectonic faults. The viscosity of such fluids may vary over seven orders of magnitude, from $10^{-4} \mathrm{~Pa}$ s for liquid water to $10^{3} \mathrm{~Pa}$ s for silicic melts at high temperature ${ }^{1-3}$. Elastohydrodynamic lubrication (EHD), or the weakening induced by overpressure generated by the shearing of a thin viscous fluid between two subparallel and rough surfaces ${ }^{4}$, has been recognised for a long time in industrial processes 5,6 . EHD has also been invoked to explain the dramatic reduction of friction during earthquake slip in the presence of fluids ${ }^{7,8}$. However, up to date, the possible triggering of EHD in natural faults relies on theoretical models only, and was not tested at deformation conditions typical of seismic faulting. Furthermore, the experimental studies investigating fluid-rock interaction almost exclusively considered water ${ }^{9-11}$ as the fluid at both subseismic and seismic slip-rates ${ }^{12}$.

For sake of simplicity, tectonic faults can be described at seismogenic depths as rough surfaces separating two solids, which are in contact at a number of asperities ${ }^{13}$, which represent only a fraction of the total fault area, and can be filled by fluids and gouges. During fault sliding and depending on how the normal stress is partitioned between the asperities and the fluid, three different regimes can been distinguished 4,14 : the boundary lubrication regime (BL), where the normal stress is supported by solid-solid contacts; the fully lubricated regime (EHD), where the normal stress is supported by interstitial fluid; and the mixed lubrication regime (ML), where the normal stress is supported both by the solid-solid contacts and the fluid. The transition between these three regimes is controlled by the Sommerfeld number $4=\frac{6 \eta V L}{\left(H_{0}\right)^{2} \sigma_{\text {eff }}}$, where $V$ is the slip-rate, $\eta$ is the lubricant dynamic viscosity at the estimated mean temperature ${ }^{14}$ of the slipping zone (defined as the zone where deformation is highly localised), $L$ is the characteristic length over which the fluid pressure changes (related to the wavelength of the asperities), $H_{0}$ is the initial average gap between the asperities (related to the height of the asperities) and $\sigma_{\text {eff }}$ is the effective normal stress $\left(\sigma_{\text {eff }}=\sigma_{n}-P_{f}\right.$, where $\sigma_{n}$ is the normal stress and $P_{f}$ is the fluid pressure).

Recently, Bayart et al. ${ }^{15,16}$ provided evidence of the influence of fluid viscosity by performing laboratory stick-slip experiments as an analogue of seismic events ${ }^{17}$. The setup consisted of polymethylmethacrylate (PMMA) slabs lubricated by a film of viscous fluid (silicone and hydrocarbon oils). The presence of the fluid resulted in a smaller static friction with respect to that under room-humidity conditions. However, the fracture energy (i.e., the energy dissipated by crack propagation) increased in the presence of the fluid and was independent of the lubricant viscosity but dependent of the lubricant composition.

Here, based on experimental and geological evidence, we discuss the effect of the viscosity of a fluid sandwiched between two rock slip surfaces at slip-rates characteristic of either earthquake nucleation (slip-rate from $\mu \mathrm{m} / \mathrm{s}$ to $\mathrm{mm} / \mathrm{s})^{18}$ and propagation $(\mathrm{mm} / \mathrm{s} \text { to } \mathrm{m} / \mathrm{s})^{19,20}$ and, in general, at slip-rates at which the ML and the EHD regimes might be activated.

\section{Results}

Experimental protocol. We performed 36 experiments with the rotary machine SHIVA ${ }^{21}$ (INGV, Rome) on full cylinders (diameter $D=50 \mathrm{~mm}$ ) of Westerly Granite and Carrara Marble either in the presence of a liquid lubricant or under roomhumidity conditions. Pore fluid experiments were performed under drained conditions (a membrane pump maintained a constant fluid pressure of $P_{f}=3 \mathrm{MPa}$ ), preventing macroscopic fluid pressurisation inside the vessel ${ }^{9}$. The experiments were performed by imposing a slip acceleration of $6.5 \mathrm{~m} \mathrm{~s}^{-2}$ to the samples up to a target slip-rate $(V)$, followed by deceleration to
$V=0 \mathrm{~m} / \mathrm{s}$. The target $V$ ranged from 0.01 to $1000 \mathrm{~mm} / \mathrm{s}$, slip distance $(U)$ from 0.1 to $4 \mathrm{~m}$ and imposed $\left(\sigma_{n}\right)$ were up to $23 \mathrm{MPa}$ (Supplementary Table 1). Westerly Granite and Carrara Marble were selected because (1) of their low porosity $(<2 \%$ measured using the triple-weighing method ${ }^{22}$ ), which limited fluid diffusion through the rock matrix out of the sliding surface during the experiments, (2) of their very small grain size and homogeneity and (3) because typical rocks of the seismogenic continental crust $^{23}$

The sliding surfaces of all the samples were roughened by using $120 \mathrm{SiC}$ abrasive paper $\left(H_{0} \sim \mathrm{RMS}=7-13 \mu \mathrm{m}\right.$, for Carrara Marble and Westerly Granite, respectively, measured with optical 3D profilometer, Contour GT-I 3D-Optical Microscope, Bruker). We consider the perimeter of our sample $(0.157 \mathrm{~m})$ as the maximum characteristic wavelength (i.e., the largest possible wavelength), due to the periodicity of rotation of the rock cylinders.

Fluids viscosity. Various viscosities of the lubricant were obtained by mixing different volume proportions of distilled water to $99.9 \%$ glycerol. Glycerol $(1,2,3$-propanetriol) is a Newtonian, water-soluble, colourless fluid, which is stable under most conditions due to its high flash and fire points (177 and 207 ${ }^{\circ} \mathrm{C}$, respectively), which prevents phase changes and fire hazards when exposed to high temperatures due to frictional heating. The viscosities at room temperature were $1.002 \mathrm{mPa}$ s (pure distilled water), $10.8 \mathrm{mPa}$ s (60 wt\% glycerol), $109.2 \mathrm{mPa}$ s ( $85 \mathrm{wt} \%$ glycerol), and $1226.6 \mathrm{mPa}$ s (99.9\% pure glycerol). The temperature increase with increasing slip due to frictional heating during the experiments is expected to lower the lubricant viscosity. The increase in the bulk temperature on the shearing surfaces was estimated by using a 2D time-dependent model for heat diffusion. We assumed that all the mechanical energy was converted into heat (because wear products were almost negligible in the fluid lubricated regime) and we neglected heat losses by radiation and fluid convection (the liquid was inside a vessel). As a consequence, half the instantaneous heat flow-rate $Q(r, t)=0.5 \times \tau(t) \times V(r, t)$, where $r$ is the radial distance from the centre of the sample, $\tau$ is the shear stress, was applied as a Neumann boundary condition ${ }^{24}$ to the edge of the model, which simulates the slip surface. Then, the estimated temperature at $r=$ $2 / 3 R$ where $R=25 \mathrm{~mm}$ is the external radius of the sample, was used to correct the fluid viscosity following the empirical formula proposed by Cheng ${ }^{25}$ and to compute $S$ (Supplementary Figure 8 and Supplementary Table 5 for detail on the thermal model).

Mechanical results. The apparent friction coefficient $(\mu)$ is the ratio of the shear stress to the effective normal stress. For both rock types, at the beginning of the experiments, the shear stress acting on the fault increased until the static friction coefficient $\mu_{\text {static }}$ was overcome and slip initiated (Fig. 1). Immediately after slip initiation, a further increase in $\mu$ was observed (indicating slip-strengthening behaviour) until a peak friction $\mu_{\text {peak }}$ was achieved at $V \sim 1 \mathrm{~mm} / \mathrm{s}$ when the target $V$ was higher than $1 \mathrm{~mm} /$ s. Subsequently, $\mu$ decreased with slip to a minimum and approximately steady-state dynamic friction coefficient $\left(\mu_{\text {dyn }}\right)$ during a transient slip weakening phase over a slip distance $\left(D_{c}\right)^{26}$ (Fig. 1a). In our experiments, the achievement of this so called steady-state dynamic friction coefficient condition requires slips of several millimetres to tens of centimetres depending on the applied effective normal stress ${ }^{2}$, though steady-state conditions might not ever be achieved in nature ${ }^{27}$. Under the same acceleration conditions, the magnitude of the friction drop $\left(\mu_{\text {peak }}-\right.$ $\left.\mu_{\text {dyn }}\right)$ increased with $V$. We studied the dependency of $\mu_{\text {static }}$ and $\mu_{\text {peak }}$ with $\eta$ and S, respectively, for all the experiments (Fig. 1). Independently of the rock type, $\mu_{\text {static }}$ slightly decreased from 

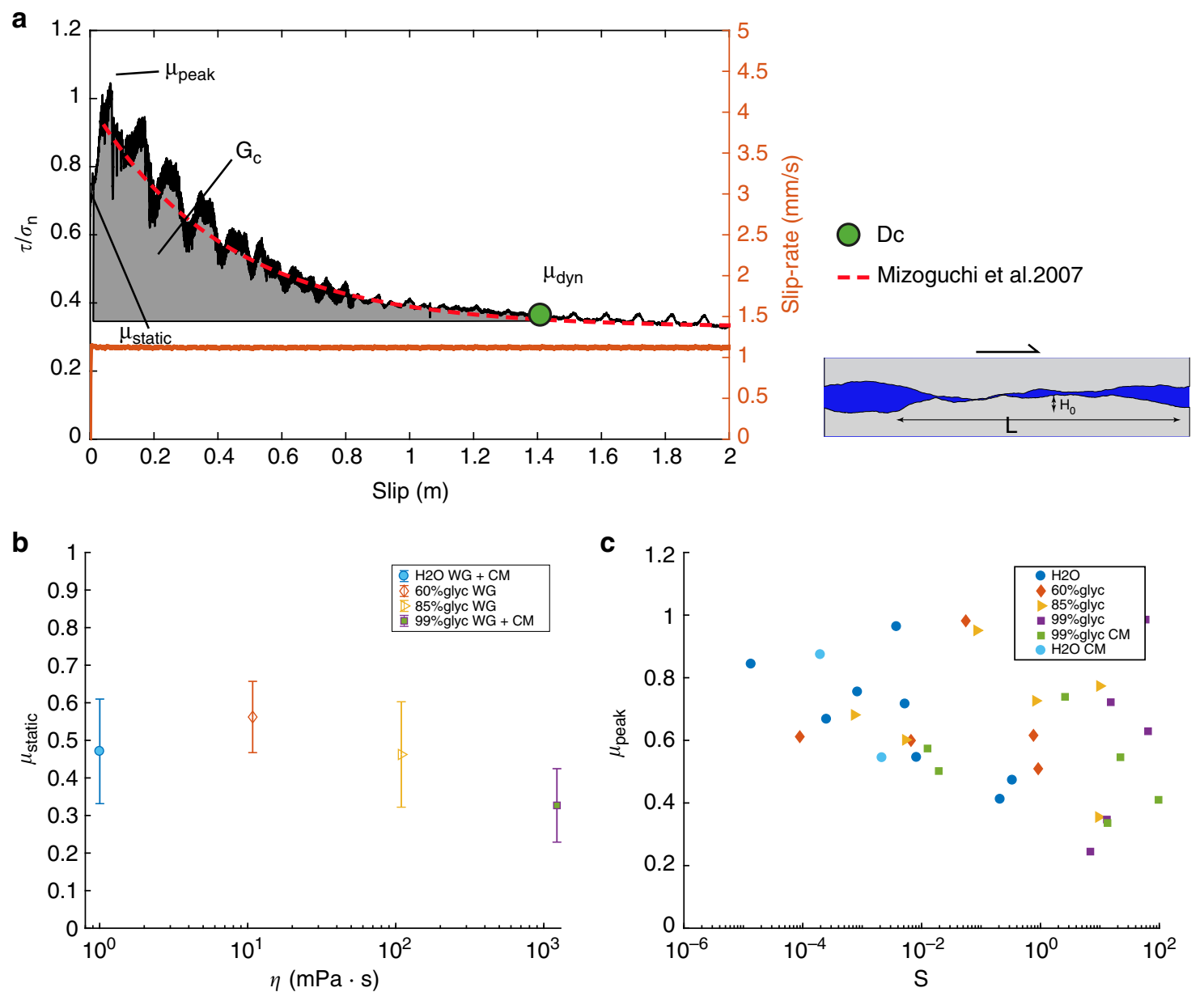

Fig. 1 Apparent friction coefficient vs. slip, friction coefficients vs. viscosity, and Sommerfeld number. Experiments were performed at an acceleration of $6.5 \mathrm{~m} \mathrm{~s}^{-2}$ and effective normal stress $\sigma_{\text {eff }}$ up to $20 \mathrm{MPa}$, under the following environmental and hydraulic conditions: $100 \%$ water $\left(\mathrm{H}_{2} \mathrm{O}\right.$, blue in colour dots), $60 \%$ glycerol/40\% water (orange diamonds), $85 \%$ glycerol/15\% water (yellow triangles), and pure glycerol (99\% glycerol, purple squares).

a Apparent friction coefficient vs. slip for experiment $\mathrm{S} 1315$ performed at $\sigma_{\text {eff }}=10 \mathrm{MPa}$ in the presence of mixture $60 \%$ glycerol/40\% water. $\mu_{\text {static },} \mu_{\text {peak, }}$ $\mu_{\mathrm{dyn},} G_{\mathrm{c}}$ and $D_{\mathrm{c}}$ are represented. The apparent friction coefficient is fitted following the exponential decay function proposed by Mizoguchi et al. ${ }^{26:}$ $\mu=\mu_{\text {dyn }}+\left(\mu_{\text {peak }}-\mu_{\text {dyn }}\right) e^{\ln (0.05) U / D_{c}}$ (red line). The $G_{\mathrm{c}}$ is define as $G_{c}=D_{c} \tau d u$ where the weakening distance $D_{c}$ is the displacement over which $\mu_{\text {dyn }}$ is $95 \%$ of $\left(\mu_{\text {peak }}-\mu_{\mathrm{dyn}}\right)$ (Mizoguchi et al. $\left.{ }^{26}\right)$. b Static friction coefficient vs. viscosity $\eta$. The error bar indicate the standard deviation from the reported average values. In the semi-logarithmic diagram, the static friction coefficient slightly decreases linearly with increasing $\eta$ (all values are reported in Supplementary Table 1). c Peak friction coefficients vs. Sommerfeld number

$\sim 0.55$ at $\eta_{0}=10.8 \mathrm{mPa} s$ to $\sim 0.33$ at $\eta_{0}=1226 \mathrm{mPa} \mathrm{s}$ (Fig. $1 \mathrm{~b}$ ). Instead, the $\mu_{\text {peak }}$ was $0.651 \pm 0.222$ (highly scattered) over the entire range of $S$ (Fig. 1c), had no significant correlation with either $V$ (Supplementary Figure 5) or $\eta$, and its average value was similar to the $\mu_{\text {peak }}$ obtained under room-humidity conditions ${ }^{28}$.

The $\mu_{\text {dyn }}$ varied with $S$ (Fig. 2): for $S<10^{-3}, \mu_{\text {dyn }}$ was $\sim 0.70 \pm 0.05$ and nearly independent of $S$ (velocity neutral, or BL regime); at $10^{-3}<S<1, \mu_{\text {dyn }}$ decayed with $S$ from $\sim 0.7\left(S=10^{-3}\right)$ to $\sim 0.2(S=$ 1) (ML regime); at $S>1, \mu_{\text {dyn }}$ slightly increased with increasing sliprate (EHD regime). This Stribeck-type behaviour was similar for both water and water/glycerol mixtures but shifted to greater $S$ values for the latter (Supplementary Figure 6). Importantly, the behaviour is similar for the two rock types suggesting that the obtained Stribeck curve relates to the rheology of the fluid mixtures rather than to the peculiar dynamic weakening mechanism of granite (flash and bulk melting ${ }^{2}$ ) or Carrara Marble (temperature and grain-size dependent ${ }^{29}$ ). Note that $\mu_{\text {dyn }}$ slightly decreased with increasing $V$ as proposed by Di Toro et al. ${ }^{2}$, but was high scattered (Supplementary Figure 5).

Following the Stribeck model proposed by Canudas de Wit et $\mathrm{al}^{30}$ and based on the solution on motion at so-called steady state conditions for metallic frictional interfaces, our friction data can be described by:

$$
\mu_{\mathrm{dyn}}=\mu_{\mathrm{c}}+\left(\mu_{\mathrm{static}}-\mu_{\mathrm{c}}\right) \cdot e^{-\beta \sqrt{S}}+\gamma \cdot S
$$

where $\mu_{\text {static }}(=0.7)$ is the Coulomb friction coefficient corresponding to $\mu_{\text {static }}$ under dry conditions (i.e., without fluid lubrication), $\mu_{\mathrm{c}}(=0.1)$ is the friction coefficient at the full film lubrication condition $\left(\sim \mu_{\mathrm{dyn}}\right.$ during EHD), and $\beta$ and $\gamma$ are empirically determined linear coefficients. The second and the third right-hand terms of Eq. (1) depict, respectively, the Stribeck effect (the decrease in the friction coefficient due to an increase in $V$ ) and the viscous friction (the increase in the friction coefficient due to the presence of viscous fluids). We used a linear regression procedure to estimate the coefficients $\beta$ and $\gamma$ for the for the original experimental dataset presented here (Supplementary Table 2), plus published experimental and field data (from Eq. (1), coefficient of determination $R^{2}=0.90, \beta=8.03$, and $\gamma=$ 0.004) (Fig. 2). In fact, this relation holds for other silicate-bearing rocks (gabbro, peridotite, etc. ${ }^{10,31-33}$ ) tested at seismic slip conditions, and where frictional melting occurred, highlighting 


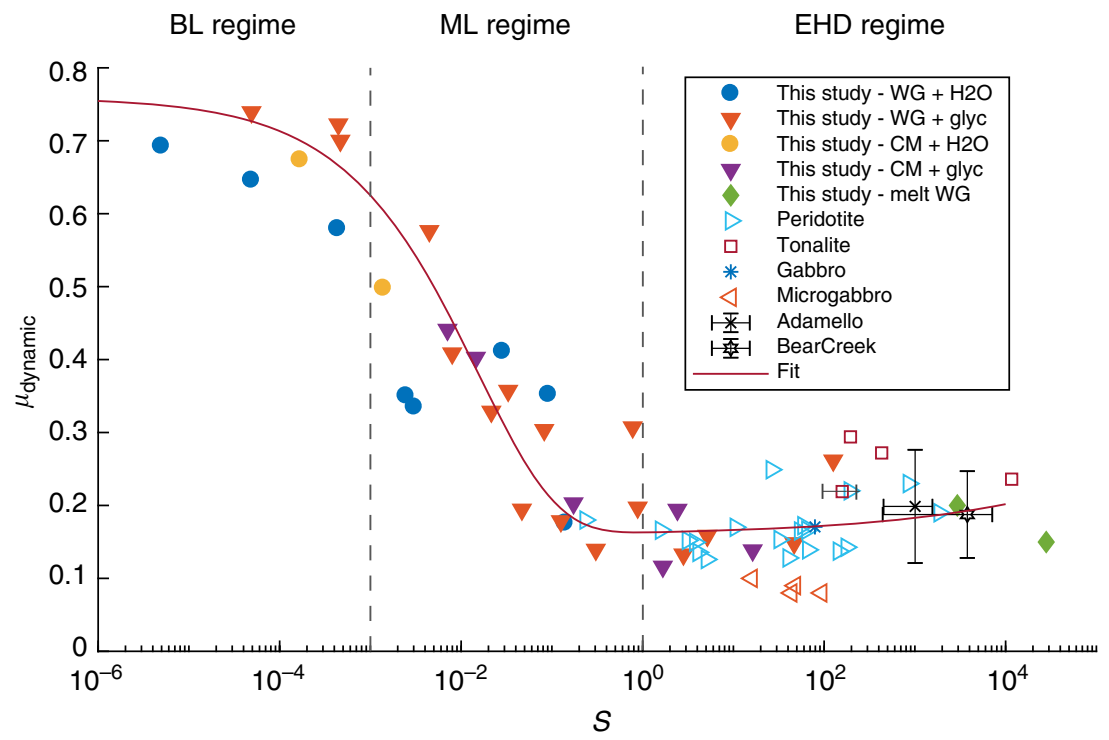

Fig. 2 Dynamic friction coefficient vs. Sommerfeld number. Experiments performed in water and glycerol presented in this study are compared with previous experiments with evidence of frictional melting performed on peridotite ${ }^{31}$, tonalite ${ }^{32}$, gabbro ${ }^{33}$, and microgabbro ${ }^{10}$ (see symbols in the figure with WG for Westerly Granite and CM for Carrara Marble, see Supplementary Material Table 5). The viscosity of the melt for the room-humidity experiments were computed using the formulas proposed by Giordano et al. ${ }^{50}$. The $H_{0}$ values were considered constant for the experiments performed in presence of melt and equal to 13 $\mu \mathrm{m}$. The two black points with large error bars refer to field estimation of S from pseudotachylyte-bearing faults (Gole Larghe fault zone in Adamello (Italy) and Bear Creek fault zone in Mount Abbot Quadrangle (USA)), see Supplementary Note 1. For $S<10^{-3}$, boundary lubrication regime, the dynamic friction coefficient is almost independent of $S$. For $10^{-3}<S<1$, mixed lubrication regime, the dynamic friction coefficient decreases drastically with increasing $S$. For $S>1$, elastohydrodynamic lubrication regime, the dynamic friction increases slightly with $S$. The best-fit curves are obtained using Eq. (1) (main text) with coefficients of determination of $R^{2}=0.90$. The scattering in $\mu_{\mathrm{dyn}}$ for $S \geq 1$ is attributable to the viscosity of the fluid given that $\tau \propto \eta V$

the universality of EHD mechanism when fluids are present in the fault slipping zone (Fig. 2).

Microstructural investigation of the slipping zones (Supplementary Figure 2) recovered after the experiments performed on Westerly Granite at $V=1 \mathrm{~m} / \mathrm{s}$ under room-humidity and water conditions (corresponding to $S<1$ ), showed evidence of frictional melting ${ }^{34}$. Instead, there was no evidence of frictional melting in the slipping zones recovered from the experiments conducted on 85 and $99 \%$ of glycerol where the fully lubricated regime $(S>1)$ was achieved (Supplementary Figure 2). Moreover, for $S>1$ the roughness of the slip surfaces at the end of the experiments was comparable to the initial roughness (Supplementary Figure 3). In the case of Carrara marble, the slipping zone after the experiments conducted at $V>0.1 \mathrm{~m} / \mathrm{s}$ under either room humidity ${ }^{9}$ or waterflooded conditions when $S<1$, was made of submicrometre in size (recrystallised) grains. Instead, there were no slipping zones made of submicrometre in size grains after the experiments conducted with 99\% glycerol and at high slip-rate where the fully lubricated regime $(S>1)$ was achieved (Supplementary Figure 4). As was the case for the experiments performed on Westerly Granite, the sheared samples had a surface roughness very similar to the initial nonsheared one. In conclusion, microstructural observation and surface roughness measurements suggest that for $S>1$ most of the shearing was accomodated within the glycerine-rich fluid, confirming the activation and effectiveness of EHD lubrication.

Rupture propagation criteria and extrapolation to natural case. We now briefly discuss to what degree the lubrication processes measured here may promote rupture propagation and earthquake slip in a faulting scenario. Increasing $S$ reduced the dynamic friction coefficient $\left(\mu_{\text {dyn }}\right)$ (Fig. 2); however, this will come at the cost of increasing the fracture energy $\left(G_{c}\right)$, at least in the $\mathrm{BL}$ and $\mathrm{ML}$ regimes $(S>1)$ (Fig. 3). Indeed, $G_{\mathrm{c}}$ increased exponentially with $S$ in $\mathrm{BL}$ and $\mathrm{ML}$ regime, i.e., $S<1$ up to $9 \mathrm{MJ} \mathrm{m}^{-2}$. Instead, at the boundary between the ML and the EHD regimes, $G_{c}$ dropped sharply back to values of $\sim 1 \mathrm{MJ} \mathrm{m}^{-2}$, evidencing the transition between ML and EHD regimes. Therefore, lubrication affects two competing mechanisms and does not necessarily promote dynamic earthquake rupture propagation.

To illustrate this, we may write a simplified rupture propagation criterion as

$$
\frac{1}{2}\left(\tau_{0}-\tau_{\text {dyn }}(S)\right) U \geq G_{\mathrm{c}}(S),
$$

where $\tau_{0}$ is the initial shear stress on the fault (whose upper bound is $\left.\left.\tau_{\text {static }}=\mu_{\text {static }} \sigma_{\text {eff }}\right), \tau_{\text {dyn }}=\mu_{\text {dyn }} \sigma_{\text {eff }}\right)$, and where the $S$ dependence of $\tau_{\text {dyn }}(S)$ and $G_{c}(S)$ is made explicit. As seen in the left-hand term, the effectiveness of lubrication increases with the amount of fault slip $U$. A large value of $G_{c}$ may prevent the dynamic propagation of smaller earthquakes, but as $U$ increases the lubrication effect will become dominant. Because fracture energy will remain constant after the critical slip distance $U=D_{\mathrm{c}}$ (Fig. 1a), but the left-hand side of Eq. (2) will continue to increase with slip, the indicative value $U \approx D_{\text {c }}$ will mark the watershed between rupture-hindering and rupture-promotion by lubrication under intermediate $S$ values. Note that when $S>1$, both $G_{\mathrm{c}}$ and $\mu_{\text {dyn }}$ are small, favouring earthquake propagation.

While our experimental protocol allows us to impose and estimate the parameters $\left(\eta, V, \sigma_{\text {eff }}, L / H_{0}\right)$ which control $S$, the same parameters are poorly known in nature. Here, below we attempt an estimate of the possible ranges of $\left(\eta, V, \sigma_{\text {eff }}, L / H_{0}\right)$ for natural faults. Water is pervasive in the Earth's crust ${ }^{8,35-37}$ : the viscosity of water ranges from $\sim 1 \mathrm{mPa}$ s at subsurface conditions ( $\sim 1 \mathrm{~km}$ depth) to $\sim 0.1 \mathrm{mPa}$ at a depth of $10 \mathrm{~km}$ (considering a thermal gradient of $30^{\circ} \mathrm{C} / \mathrm{km}$ and a linear increase in $\sigma_{\text {eff }}$ with depth; Supplementary Figure 9). Alternatively, viscous fluids along faults may be produced by frictional melting during seismic slip $^{2}$; a minimum value of $10 \mathrm{Pas}$ has been estimated ${ }^{33}$ for frictional melt viscosity. Moreover, especially in the shallower 

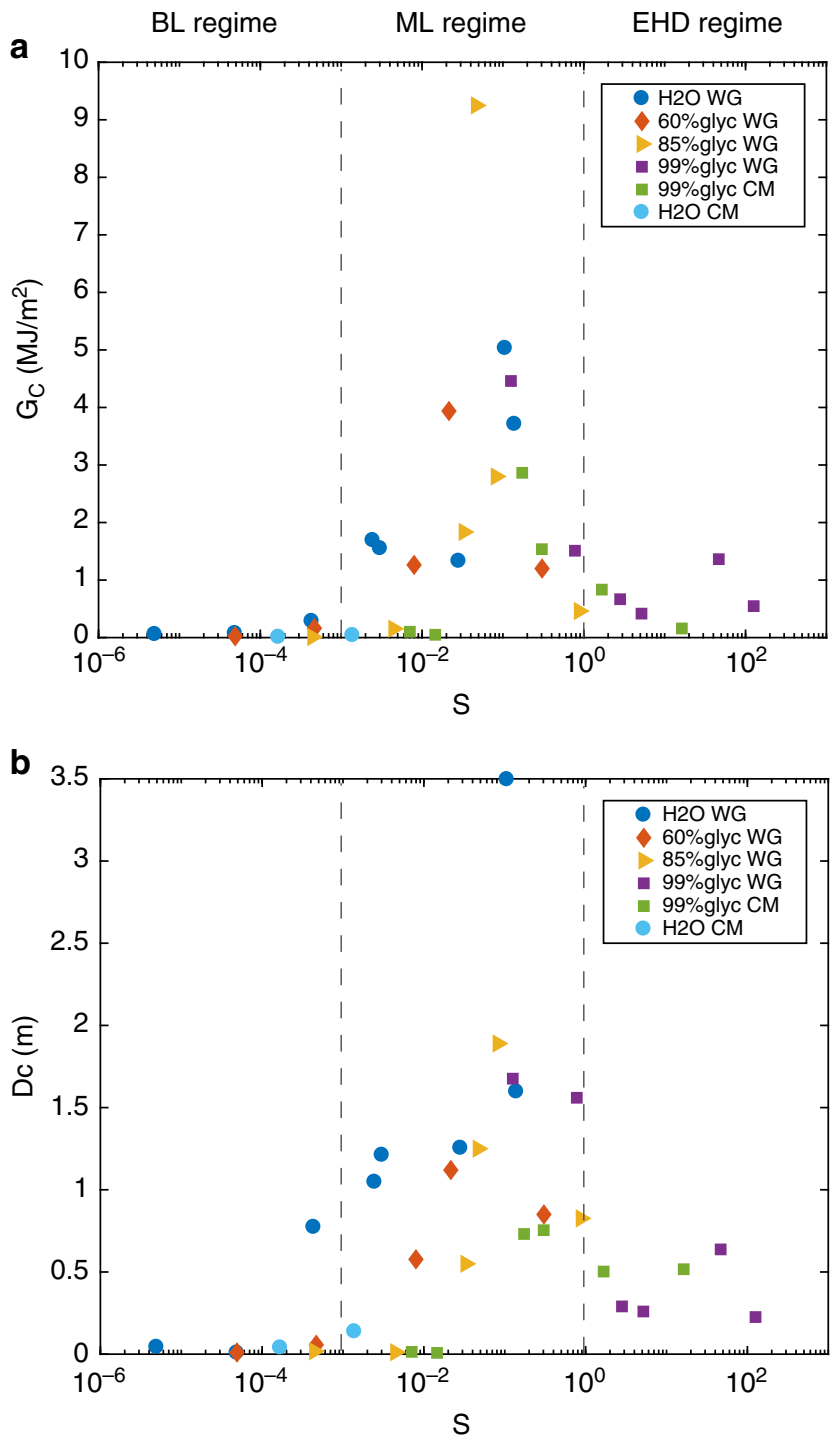

Fig. 3 Fracture energy and $D_{\mathrm{c}}$ vs. Sommerfeld number. The three lubrication regimes (BL, ML, and EHD) are delimited by vertical black dashed lines. Experiments were performed at acceleration of $6.5 \mathrm{~m} \mathrm{~s}^{-2}$, effective normal stress $\sigma_{\text {eff }}$ up to $20 \mathrm{MPa}$ in the presence of water, mixtures of glycerol, and water and pure glycerol (see symbols in the figure where WG is Westerly Granite and CM is Carrara Marble. a Fracture energy vs. Sommerfeld number. b Slip weakening distance $D_{\mathrm{c}}$ vs. Sommerfeld number

section $(<5 \mathrm{~km})$ of the seismogenic continental faults, fine grain gouge material mixed with water may also act as lubricant whose viscosity depends on the gouge grain size and the solid volume fraction. Viscosities of $\sim 10 \mathrm{~Pa}$ s have been estimated for such fluid-saturated gouges ${ }^{38-40}$. Moreover, fluids commonly used in hydraulic fracturing operations in engineering reservoirs have viscosities ranging between $1 \mathrm{mPa}$ and $1 \mathrm{~Pa}$. As a result, the viscosity of fluids in the upper crust is estimated to range from $0.1 \mathrm{mPa}$ s to more than $10 \mathrm{~Pa}$.

A value of $1 \mathrm{~m} / \mathrm{s}$ is widely accepted ${ }^{20}$ as indicative of fault seismic slip-rate. The $L$ parameter in $S$ under EHD conditions corresponds to the longest (and dominant) wavelength in the mismatch between two rough sliding surfaces. In natural faults, $L$ corresponds to the asperity wavelength, the longest of which is proportional to slip ${ }^{4}$ (and the magnitude) during a given earthquake. For earthquakes of magnitude ranging between 1 and 8 , the average seismic slip and thus $L=1 \mathrm{~mm}-4 \mathrm{~m}^{41}$. Natural faults' surface roughness is almost self-similar ${ }^{42}$ with a ratio $\frac{L}{H_{0}} \sim 1000: H_{0}$ is ranging between 0.001 to $4 \mathrm{~mm}$ for a $\mathrm{M} 1$ earthquake and M8 earthquake respectively. The lithostatic stress $\sigma_{1}=\rho_{r g} g$ (with $\rho_{r}=2700 \mathrm{~kg} / \mathrm{m}^{3}$ rock density, $z$ depth and $g$ gravity) minus the hydrostatic water pressure (with $\left.\rho_{w}=1000 \mathrm{~kg} / \mathrm{m}^{3}\right)$ at the earthquake hypocentral depth yields as an indicative value of $\sigma_{\text {eff }}=\left(\rho_{r}-\rho_{w}\right) g z / K$, with $K=\frac{1+\sin (\phi)}{1-\sin (\phi)}$, friction angle $\phi=\arctan (\mu), \mu=0.75$, acting on the fault; this results in $\sigma_{\mathrm{eff}}$ ranging from $\sim 50 \mathrm{MPa}$ (at $z=3 \mathrm{~km}$ ) to $\sim 170 \mathrm{MPa}$ (at $z=10 \mathrm{~km}$ ).

The above hypothesis for the range of parameters $(V=4 \mathrm{~m} / \mathrm{s}$, $L=1 \mathrm{~mm}-4 \mathrm{~m}, H_{0} \sim 0.001-4 \mathrm{~mm}, \sigma_{\text {eff }} \leq 170 \mathrm{Mpa}, \eta(P, T)$ ofwater) would results in $S$ values ranging from $5.0 \times 10^{-3}$ to $1.0 \times 10^{-6}$ at $z=10 \mathrm{~km}$ for $\mathrm{Mw}=1$ to $\mathrm{Mw}=8$ and from 70 to 0.07 at $z \sim 0 \mathrm{~km}$ for $M w=1$ to $M w=8$ (Supplementary Figure 9). These ranges for $S$ are comparable to the $S$ value obtained in our experiments, implying that BL, ML and EHD regimes can occur in the Earth's crust, depending on fluid viscosity, slip-rate and earthquake nucleation depth (Supplementary Figure 10), While the Somerfield number remains undetermined in most natural faults, few of well-exposed seismogenic fault zones (Gole Larghe and Bear Creek fault zones, Supplementary Note 1 and Supplementary Table 3 for details) where large scale roughness, nucleation depth and co-seismic velocity have been estimated and the occurrence of co-seismic fluids is attested by the presence of pseudotachylytes (solidified friction melts produced during seismic slip) support the trend of dynamic friction indicated by our laboratory tests (Fig. 2). This geological evidence support the hypothesis that EHD can operate in some natural earthquakes.

We have experimentally demonstrated that fluid pressure and $\eta$ are critical parameters that control slip dynamics in experimental faults and we suggest that similar effects should be expected in the case of both man-induced and natural earthquakes. In particular, highly viscous fluids (1) slightly reduce the static friction coefficient fostering fault reactivation and (2) trigger EHD lubrication during seismic slip. However, in our experimental results, for a large range of possible viscosity values of fault-permeating fluids, typical seismic slip-rates would result in intermediate values of the Sommerfeld number $\left(10^{-3}<S<1\right)$ and relatively large $D_{c}$ values. As a consequence the fracture energy during seismic propagation of small events $\left(U<D_{c}\right)$ is relatively large, inhibiting seismic rupture propagation in favour of slow strain energy relaxation by stable creep ( $S$ and $D_{c}$ would both decrease at low slip-rate). In contrast, the presence of increasingly viscous fluids decreases the fracture energy dissipated for large events, making the fault weaker. Therefore, our results suggest that in the presence of highly viscous fluids, rupture is expected to grow quasi-statically on the fault until the slip of the order of tens of $\mathrm{cm}$ is attained (until the distance $D_{\mathrm{c}}$ is overcome). While the effect of fluid pressure in earthquake rupture has been previously explored mostly in terms of thermal pressurisation and effective stress, we argue that the role of fluid viscosity is also important in understanding the dynamics of a lubricated fault system, with implications for rupture energy budget and dynamic weakening of both natural and man-induced earthquakes.

\section{Methods}

Experimental procedure. The experiments were performed with SHIVA (slow to high velocity apparatus) ${ }^{21}$, a rotary shear machines installed in Rome, on full cylinder samples of Westerly granite and Carrara marble. Target slip-rates $(V)$ ranged from $10 \mu \mathrm{m} / \mathrm{s}$ up to $3 \mathrm{~m} / \mathrm{s}$, acceleration and deceleration ramps were imposed to $6.5 \mathrm{~m} / \mathrm{s}^{2}$ and normal stresses were up to $\sigma_{n}=22.6 \mathrm{MPa}$. Mechanical data (axial load, torque, axial displacement and angular rotation) were acquired at a frequency between $250 \mathrm{~Hz}$ and $25 \mathrm{kHz}$, depending on the target slip-rate. Slip, slip-rate and shear stress were determined using the method outlined in Niemeijer et al. ${ }^{43}$ and Tsutsumi and Shimamoto $^{44}$. All the experiments (Supplementary Table 1) with fluids were performed under drained condition (i.e., pore pressure remained constant during the experi-

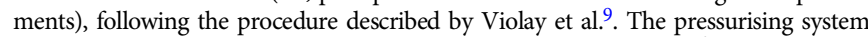
consisted of a pore fluid vessel and a membrane pump with a $30 \mathrm{~cm}^{3}$ fluid capacity, a 
pressure multiplier which imposes up to $15 \mathrm{MPa}$ of fluid pressure, a pressure regulator and valves and pipes.

In Supplementary Figure 1 we show the evolution of the apparent friction coefficient $\mu$ vs. displacement for four different experiments performed with SHIVA under $10 \mathrm{MPa}$ of effective normal stress $\left(\sigma_{\text {eff }}\right)$, in presence of different mixtures of distilled water and glycerol in order to have an initial viscosity $\eta_{0}$ increasing of a factor ca. 10, with a fluid pressure $P_{f}=2.7 \mathrm{MPa}$. In the figure, the apparent friction coefficient is fitted following the exponential decay function proposed by Mizoguchi et al. ${ }^{26} \mu=$ $\mu_{\mathrm{dyn}}+\left(\mu_{\text {peak }}-\mu_{\mathrm{dyn}}\right) e^{\frac{h(0.05) U}{D_{\mathrm{c}}}}$ and allow us to calculate the weakening distance $D_{\mathrm{c}}$.

Surface roughness measurements. The $3 \mathrm{D}$ arithmetic surface roughness was determined on the sliding surface of 20 or $25 \mathrm{~mm}$ in diameter cores of the starting samples and post-mortem samples of Westerly granite and Carrara Marble using an optical profilometer ContourGT-I 3D Optical Microscope, Bruker Nano surfaces Division. The scan of the surfaces was performed imposing an overlap of $20 \%$ between two adjacent areas. RMS (root-mean-square) and the stitched images of the samples surface of Westerly Granite after the experiments performed under room humidity condition and in presence of the four different fluids at slip-rate of $1 \mathrm{~m} / \mathrm{s}$ are shown in the Supplementary Figure 2. The RMS of the starting sample of Westerly Granite was around $13 \mu \mathrm{m}$. Measurement of roughness of Carrara Marble starting sample had an RMS $=7.05 \mu \mathrm{m}$ (Supplementary Figure 4a).

The scan of postmortem surfaces for experiments performed in presence of the same lubricant (glycerol 99), but slided at different slip-rate, had roughness of the same order of magnitude when $S \geq 1$ (Supplementary Figure 4c, Supplementary Figure $4 \mathrm{~d}$ ), and roughness of two order of magnitude higher for $S<1$ (Supplementary Figure $4 \mathrm{~b}$ ).

When the Sommerfeld number $S$ was higher than 1, the RMS of the samples at the end of the experiments was of the same order of magnitude of the initial RMS. In the experiments performed at high slip-rate the presence of high-viscous lubricants prevented the formation of melt and debris on the surfaces of Westerly Granite and Carrara Marble samples.

LuGre dynamic friction model. The LuGre dynamic friction model was proposed by Canudas de Wit et al. ${ }^{30}$ to describe friction forces as a function of slip-rate in the three lubrication regimes (boundary, mixed and elasto-hydrodynamic lubrication) in presence of viscous fluids. In this model, the behaviour of the asperities and/or the fluid during shearing is assimilated to the behaviour of some bristles whose deflection can be described as

$$
\frac{d z}{d t}=v-\frac{|v|}{g(v)} z
$$

where $z$ is the deflection of the bristles, $v$ is the slip rate and at steady state $z_{\mathrm{ss}}=g(v)$ $\operatorname{sgn}(z)$. The friction generated from the bending of the bristles is

$$
F=\sigma_{0} z+\sigma_{1} \frac{d z}{d t}+\sigma_{2} v,
$$

where $\sigma_{0}$ is the stiffness, $\sigma_{1}$ a damping coefficient and $\sigma_{2}$ a viscous coefficient.

According to the model, in mixed and hydrodynamic regimes, the friction force for constant slip-rate at steady state is given by:

$$
F_{\text {ss }}=g(v) \operatorname{sgn}(v)+f(v),
$$

where $g(v)$ seizes Coulomb friction and the Stribeck effect and it can be written as $g(v)=F_{\mathrm{c}}+\left(F_{\mathrm{s}}-F_{\mathrm{c}}\right) e^{-\left|\frac{v}{v_{\mathrm{s}}}\right|^{\alpha}}$, where $F_{\mathrm{s}}$ corresponds to the stiction force (i.e., the force necessary to start the motion), and $F_{c}$ is the Coulomb friction force, i.e., the force necessary to continue sliding in absence of lubricants, $v$ is the relative slip-rate between the moving solid bodies. The characteristic slip-rate of the Stribeck function $v_{s}$ determines how quickly $g(v)$ approaches $F_{\mathrm{c}}$ and depends on fluid viscosity and loading conditions. As suggested by Bo and Pavalescu ${ }^{45}$, the $\alpha$ parameter ranges between 0.5 and 1 . Instead, $f(v)$ is the viscous friction ${ }^{46}$ and typically is given in the form $f(v)=\sigma_{2} \cdot v^{30,47}$. In this work, we found $v_{\mathrm{s}} \propto$ $\left(\sigma_{\text {eff }} \cdot H_{0}^{2}\right) / \eta L$ and $\sigma_{2} \propto \eta L /\left(\sigma_{\text {eff }} \cdot H_{0}^{2}\right)$.

We adopted the LuGre model to fit our experimental data of $\mu_{\mathrm{dyn}}$, defined as the shear stress divided by the effective normal stress $\sigma_{\text {eff }}$ (Supplementary Figure 6), following the Eq. (1) where the coefficients $\beta$ and $\gamma$ are a function of the interaction between the rock-solid material and the molecules of the viscous fluid ${ }^{48}$.

All the parameters of the model are reported in Supplementary Table 2 and result in the best fit curves of Supplementary Figure 6.

Thermal model and viscosity correction with temperature. The increase of temperature in the slip zone and wall rocks of the sheared bulk samples during frictional sliding weas estimated using a 2D FEA time dependent model for heat diffusion.

The model reproduced the sizes of the experimental sample, (i.e., $50 \times 55 \mathrm{~mm}$ or diameter vs. height of the sample) with 1464 triangular mesh elements. Two different materials were used to simulate the slip zone and the bulk material. The slip zone was represented as a $13 \mu \mathrm{m}$-thick highly porous media. In agreement with the roughness measurements reported in Supplementary Figure 2 and Supplementary Figure 4, we considered $\phi=1-A_{\mathrm{r}} / A=0.95$ where $A_{\mathrm{r}}$ is the real contact area and $A$ is the nominal area. The bulk material was regarded as a very low porous media (3\% porosity, measured with the helium pycnometer). We assumed that all the mechanical energy is converted into heat and no heat is lost by radiation, so the heat flux $Q(r, t)=0.5 \cdot \tau$ $(t) \cdot V(r, t)$ is function of time $t$ and the the radial distance $r$ from the centre of the sample. A Neumann boundary condition was applied to the bottom external edge of the model (i.e., slip zone Supplementary Figure 5a). On the other three external boundaries, a constant temperature $T=293.15 \mathrm{~K}$ was imposed as the initial temperature of the two materials (energy dissipated by the steal of the pressure vessel). At the inner boundary between the slip zone and the wall-rock, the continuity of the solution was granted. The thermal properties of the slip zone were defined as a linear combination of the thermal properties of the fluid and of the rock which are reported in Supplementary Table 4 . The thermal diffusivity of the slip zone:

$$
\alpha_{\text {eff }}=K_{\text {eff }} /(\rho \cdot C)_{\text {eff }} \text {. }
$$

With $K_{\text {eff }}=(1-\phi) \cdot K_{r}+\phi \cdot K_{f}$ and $(\rho \cdot C)_{\text {eff }}=\left((1-\phi) \cdot \rho_{r} \cdot C_{r}\right)+\left(\phi \cdot \rho_{f} C_{f}\right)$ where $r$ and $f$ are related to the rock and fluid properties, respectively.

The diffusion of the heat is:

$$
(\rho C)_{\mathrm{eff}, i} \cdot \partial \frac{T}{\partial} t=\nabla \cdot\left(\kappa_{\mathrm{eff}, i} T\right),
$$

where $i$ identified the two materials. The temperature in the slip zone was taken when the $\mu_{\text {dyn }}$ was reached (Supplementary Figure 7b).

Using the average estimated temperature in the slip zone at $2 / 3 R(R=25 \mathrm{~mm}$ is the external radius of the sample, Supplementary Figure $7 \mathrm{c}$ ), we corrected the initial viscosities (at $20^{\circ} \mathrm{C}$ ) of the fluids exploting the empirical law proposed by Cheng ${ }^{49}$ for water/glycerol mixtures.

The dynamic viscosity $\eta$ of the mixture is:

$$
\eta=\eta_{w}^{\alpha} \cdot \eta_{\mathrm{glyc}}^{1-\alpha} .
$$

Where $\alpha$ is weighting factor, function of the concentration of glycerol $C_{m}$ and of two empirical factors $a$ and $b$ which are dependent of the temperature $T$

$$
\alpha=1-C_{m}+\frac{a(T) \cdot b(T) \cdot\left(1-C_{m}\right)}{a(T) \cdot C_{m}+b(T) \cdot\left(1-C_{m}\right)} .
$$

Supplementary Figure 8 shows the decrease of the initial fluids viscosities with increasing temperatures associated to frictional sliding.

Rupture propagation criterion. The energy change $d W[\mathrm{~J} / \mathrm{m}]$ for an advancement $d L$ of a crack of length $L$ (if homogeneous conditions are assumed and radiated energy is neglected, which is a realistic assumption for the early phase of nucleation with slow rupture velocity) can be written as:

$$
d W=-d L G_{\mathrm{c}}+\frac{1}{2} \Delta \tau L d U,
$$

where $d U=C \Delta \tau / \mu^{\prime} d L$ is the slip increment, $\mu^{\prime}$ shear stiffness, $\Delta \tau$ the stress drop and $G_{c}$ the fracture energy.

Therefore we may write the energy delivery rate in a simplified form:

$$
\frac{d W}{d L}=-G_{\mathrm{C}}+\frac{1}{2} \frac{C \Delta \tau^{2}}{\mu^{\prime}} L,
$$

with $C$ a geometrical dimensionless constant.

For the crack to propagate the requirement is that $\frac{d W}{d L} \geq 0$, therefore

$$
\frac{1}{2} C \frac{(\Delta \tau)^{2}}{\mu^{\prime}} L \geq G_{\mathrm{C}}
$$

substituting $L$ with $U$ by using $L=\mu^{\prime} /(C \Delta \tau) U$ we obtain $1 / 2 \Delta \tau U \geq C G_{c}$ where the stress drop is $\Delta \tau=\tau_{0}-\tau_{\text {dyn }}$. Therefore we obtain:

$$
\frac{1}{2}\left(\tau_{0}-\tau_{\text {dyn }}\right) U \geq G_{c} .
$$

\section{Data availability}

Correspondence and request for additional material should be addressed to chiara cornelio@epfl.ch. All the experimental raw data are available in Zenodo with the identifier "https://doi.org/10.5281/zenodo.2557665".

Received: 21 January 2019 Accepted: 26 February 2019

Published online: 20 March 2019

\section{References}

1. Spray, J. G. Viscosity determinations of some frictionally generated silicate melts: implications for fault zone rheology at high strain rates. J. Geophys. Res. Solid Earth 98, 8053-8068 (1993).

2. Di Toro, G. et al. Fault lubrication during earthquakes. Nature 471, 494-498 (2011).

3. Hirose, T. \& Shimamoto, T. Growth of molten zone as a mechanism of slip weakening of simulated faults in gabbro during frictional melting. J. Geophys. Res. B Solid Earth 110, 1-18 (2005). 
4. Brodsky, E. E. \& Kanamori, H. Elastohydrodynamic lubrication of faults. J. Geophys. Res. 106, 16,357-16,374 (2001)

5. Dowson, D. \& Longfield, M. D. An elastohydrodynamic lubrication experiment. Nature 197, 586 (1963).

6. Bair, S. \& Winer, W. O. Some observations in high pressure rheology of lubricants. J. Lubr. Technol. 104, 357-364 (1982).

7. King Hubbert, M. \& Rubey, W. W. Role of fluid pressure in mechanics of overthrust faulting. Bull. Geol. Soc. Am. 70, 115-166 (1959).

8. Lachenbruch, A. H. \& Sass, J. H. Heat flow and energetics of the San Andreas fault zone. J. Geophys. Res. 85, 6185-6222 (1980).

9. Violay, M. et al. Pore fluid in experimental calcite-bearing faults: abrupt weakening and geochemical signature of co-seismic processes. Earth Planet Sci. Lett. 361, 74-84 (2013).

10. Violay, M. et al. Effect of water on the frictional behavior of cohesive rocks during earthquakes. Geology 42, 27-30 (2014).

11. Violay, M., Di Toro, G., Nielsen, S., Spagnuolo, E. \& Burg, J. P. Thermomechanical pressurization of experimental faults in cohesive rocks during seismic slip. Earth Planet. Sci. Lett. 429, 1-10 (2015).

12. Scuderi, M. M., Collettini, C. \& Marone, C. Frictional stability and earthquake triggering during fluid pressure stimulation of an experimental fault. Earth Planet. Sci. Lett. 477, 84-96 (2017).

13. Dieterich, J. H. \& Kilgore, B. D. Direct observation of frictional contacts: new insights for state-dependent properties. Pageophysic 143, 283-302 (1994).

14. Persson, B. N. J. Sliding Friction: Physical Principles and Applications., https:// doi.org/10.1007/978-3-662-04283-0 (2000).

15. Bayart, E., Svetlizky, I. \& Fineberg, J. Fracture mechanics determine the lengths of interface ruptures that mediate frictional motion. Nat. Phys. 12, 166-171 (2016).

16. Bayart, E., Svetlizky, I. \& Fineberg, J. Slippery but tough-the rapid fracture of lubricated frictional interfaces. Phys. Rev. Lett. 116, 1-5 (2016).

17. Brace, W. F. \& Byerlee, J. D. Stick-slip as a mechanism for earthquakes. Am. Assoc. Adv. Sci. 153, 990-992 (1966).

18. Dieterich, J. H. Earthquake nucleation on faults with rate- and statedependent strength. Tectonophysics 211, 115-134 (1992)

19. Sibson, R. H. Brecciation processes in fault zones: inferences from earthquake rupturing. Pure Appl. Geophys. 124, 159-175 (1986).

20. Heaton, T. H. Evidence for and implications of self-healing pulses of slip in earthquake rupture. Phys. Earth Planet. Inter. 64, 1-20 (1990).

21. Di Toro, G. et al. From field geology to earthquake simulation: a new state-ofthe-art tool to investigate rock friction during the seismic cycle (SHIVA). Sci. Fis. Nat. 21, 95-114 (2010).

22. Violay, M., Pezard, P. A., Ildefonse, B., Belghoul, A. \& Laverne, C. Petrophysical properties of the root zone of sheeted dikes in the ocean crust: a case study from Hole ODP/IODP 1256D, Eastern Equatorial Pacific. Tectonophysics 493, 139-152 (2010).

23. Wedepohl, K. H. The composition of the continental crust. Geochim. Cosmochim. Acta 59, 1217-1232 (1995).

24. Morse, P. M. \& Feshbach, H. Methods of Theoretical Physics: Part 1. (McGrawHill, New York, Toronto, London 1953).

25. Cheng, N. S. Formula for the viscosity of a glycerol-water mixture. Ind. Eng. Chem. Res. 47, 3285-3288 (2008).

26. Mizoguchi, K., Hirose, T., Shimamoto, T. \& Fukuyama, E. Reconstruction of seismic faulting by high-velocity friction experiments: an example of the 1995 Kobe earthquake. Geophys. Res. Lett. 34 (2007).

27. Zonghu, L., Jefferson, C. C. \& Ze'ev, R. Fault strength evolution during high velocity friction experiments with slip-pulse and constant velocity loading. Earth Planet. Sci. Lett. 406, 93-101 (2014).

28. Passelègue, F. X. et al. Frictional evolution, acoustic emissions activity, and offfault damage in simulated faults sheared at seismic slip rates. J. Geophys. Res. Solid Earth 121, 7490-7513 (2016)

29. Green, H. W., Shi, F., Bozhilov, K., Xia, G. \& Reches, Z. Phase transformation and nanometric flow cause extreme weakening during fault slip. Nat. Geosci. 8, 448-489 (2015).

30. Canudas de Wit, C., Olsson, H., Astrom, K. J. \& Lischinsky, P. A new model for control of systems with friction. IEEE Trans. Autom. Contr. 40, 419-425 (1995).

31. Del Gaudio, P. et al. Frictional melting of peridotite and seismic slip. J. Geophys. Res. 114 (2009).

32. Di Toro, G., Hirose, T., Nielsen, S. \& Shimamoto, T. Relating high-velocity rock-friction experiments to coseismic slip in the presence of melts. Geophys. Monogr. Ser. 170, 121-134 (2006).

33. Nielsen, S., Di Toro, G., Hirose, T. \& Shimamoto, T. Frictional melt and seismic slip. J. Geophys. Res. 113, 1-20 (2008).

34. Passelègue, F. X. et al. Influence of fault strength on precurosy processes during laboratory earthquakes. Geophys. Monogr. Ser. 227 (2016).

35. Sibson, R. H. Interactions between temperature and pore-fluid pressure during earthquake faulting and a mechanism for partial or total stress relief. Nature 243, 66-68 (1973).

36. Rice, J. R. Heating and weakening of faults during earthquake slip. J. Geophys. Res. Solid Earth 111, 1-29 (2006).
37. Hickman, S., Sibson, R., Bruhn, R. Introduction to special section: mechanical involvement of fluids in faulting in Faulting. J. Geophys. Res. 100 (1995)

38. Major, J. J. \& Pierson, T. C. Debris flow rheology: experimental analysis of fine-grained slurries. Water Resour. Res. 28, 841-857 (1992).

39. Brodsky, E. E., Rowe, C. D., Meneghini, F. \& Moore, J. C. A geological fingerprint of low-viscosity fault fluids mobilized during an earthquake. J. Geophys. Res. Solid Earth 114, 1-14 (2009).

40. Rowe, C. D., Kirkpatrick, J. D. \& Brodsky, E. E. Fault rock injections record paleo-earthquakes. Earth Planet. Sci. Lett. 335-336, 154-166 (2012).

41. Sibson, R. H. Earthquake faulting as a structural process. J. Struct. Geol. 11, 1-14 (1989).

42. Brodsky, E. E., Kirkpatrick, J. D. \& Candela, T. Constraints from fault roughness on the scale-dependent strength of rocks. Geology 44, 19-22 (2016).

43. Niemeijer, A., Di Toro, G., Nielsen, S. \& Di Felice, F. Frictional melting of gabbro under extreme experimental conditions of normal stress, acceleration, and sliding velocity. J. Geophys. Res. Solid Earth 116, 1-18 (2011).

44. Tsutsumi, A. \& Shimamoto, T. High velocity frictional properties of gabbro. Geophys. Res. Lett. 24, 699 (1997).

45. Bo, L. C. \& Pavelescu, D. The friction-speed relation and its influence on the critical velocity of stick-slip motion. Wear 82, 277-289 (1982)

46. Reynolds, $\mathrm{O}$. On the theory of lubrication and its application to $\mathrm{Mr}$ Beauchamp Tower's experiments, including an experimental determination of the viscosity of olive oil. Philos. Trans. R. Soc. Lond. 177, 157-234 (1886).

47. Olsson, H., Åström, K. J., Canudas de Wit, C., Gäfvert, M. \& Lischinsky, P. Friction models and friction compensation. Eur. J. Control., https://doi.org/ 10.1016/S0947-3580(98)70113-X (1998).

48. Persson, B. N. J. Theory of friction: friction dynamics for boundary lubricated surfaces. Phys. Rev. B Condens. Matter 55, 8004-8012 (1997).

49. Cheng, N. Formula for Viscosity of Glycerol-Water Mixture. Industrial and Engineering Chemistry Research 47, 3285-3288 (2008).

50. Giordano, D., Russell, J. K. \& Dingwell, D. B. Viscosity of magmatic liquids: a model. Earth Planet. Sci. Lett. 271, 123-134 (2008).

\section{Acknowledgements}

This research is funded by SFOE (Swiss Federal Office of Energy) through the EDGAR project. C.C. and M.V. acknowledge EPFL for support. E.S. and G.D.T. acknowledge the ERC CoG project 614705 NOFEAR. M.V. acknowledges the European Research Council Starting Grant project 757290-BEFINE. C.C. and M.V. acknowledge professor C. Ancey and B. de Graffenried for their help with fluid viscosity measurements and scientific discussions.

\section{Author contributions}

Original idea was from C.C. and M.V. C.C., E.S. and M.V. performed the experiments. C.C performed the surface roughness measurements and developed the thermal model with input of M.V. C.C. and M.V. co-wrote the manuscript with the input of E.S., S.N. and G.D.T All the authors participated in the interpretation of the data and in the discussion of the paper.

\section{Additional information}

Supplementary Information accompanies this paper at https://doi.org/10.1038/s41467019-09293-9.

Competing interests: The authors declare no competing interests.

Reprints and permission information is available online at http://npg.nature.com/ reprintsandpermissions/

Journal peer review information: Nature Communications thanks the anonymous reviewers for their contribution to the peer review of this work.

Publisher's note: Springer Nature remains neutral with regard to jurisdictional claims in published maps and institutional affiliations.

pen Access This article is licensed under a Creative Commons Attribution 4.0 International License, which permits use, sharing, adaptation, distribution and reproduction in any medium or format, as long as you give appropriate credit to the original author(s) and the source, provide a link to the Creative Commons license, and indicate if changes were made. The images or other third party material in this article are included in the article's Creative Commons license, unless indicated otherwise in a credit line to the material. If material is not included in the article's Creative Commons license and your intended use is not permitted by statutory regulation or exceeds the permitted use, you will need to obtain permission directly from the copyright holder. To view a copy of this license, visit http://creativecommons.org/licenses/by/4.0/.

(C) The Author(s) 2019 